\title{
Receptor-Tyrosine Kinase Inhibitor Ponatinib Inhibits Meningioma Growth In Vitro and In Vivo
}

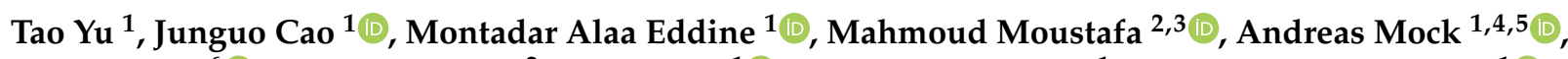 \\ Cihan Erkut ${ }^{6}\left({ }^{\circ}\right.$, Amir Abdollahi ${ }^{2}$, Rolf Warta ${ }^{1}{ }^{1}$, Andreas Unterberg ${ }^{1}$, Christel Herold-Mende ${ }^{1}(\mathbb{D})$ \\ and Gerhard Jungwirth $1, * \mathbb{C}$
}

1 Department of Neurosurgery, Division of Experimental Neurosurgery, University of Heidelberg, Im Neuenheimer Feld 400, 69120 Heidelberg, Germany; tao.yu@stud.uni-heidelberg.de (T.Y.); junguo.cao@med.uni-heidelberg.de (J.C.); mohammedmontadar.alaaeddine@med.uni-heidelberg.de (M.A.E.); andreas.mock@med.uni-heidelberg.de (A.M.); rolf.warta@med.uni-heidelberg.de (R.W.);

andreas.unterberg@med.uni-heidelberg.de (A.U.); christel.herold-mende@med.uni-heidelberg.de (C.H.-M.)

2 Department of Radiation Oncology, University of Heidelberg, Im Neuenheimer Feld 400, 69120 Heidelberg, Germany; mahmoud.moustafa@med.uni-heidelberg.de (M.M.); a.amir@dkfz-heidelberg.de (A.A.)

3 Department of Clinical Pathology, Suez Canal University, $4.5 \mathrm{Km}$ the Ring Road, Ismailia 41522, Egypt

4 National Center for Tumor Diseases (NCT) Heidelberg, Department of Medical Oncology, Heidelberg University Hospital, Im Neuenheimer Feld 400, 69120 Heidelberg, Germany

5 National Center for Tumor Diseases (NCT) Heidelberg, Department of Translational Medical Oncology, German Cancer Research Center (DKFZ), Im Neuenheimer Feld 581, 69120 Heidelberg, Germany

6 Division of Applied Functional Genomics, German Cancer Research Center (DKFZ), Im Neuenheimer Feld 581, 69120 Heidelberg, Germany; cihan.erkut@nct-heidelberg.de

* Correspondence: gerhard.jungwirth@med.uni-heidelberg.de; Tel.: +49-6221-5638-523

check for updates

Citation: Yu, T.; Cao, J.; Alaa Eddine, M.; Moustafa, M.; Mock, A.; Erkut, C.; Abdollahi, A.; Warta, R.; Unterberg, A.; Herold-Mende, C.; et al. Receptor-Tyrosine Kinase Inhibitor Ponatinib Inhibits Meningioma Growth In Vitro and In Vivo. Cancers 2021, 13, 5898. https://doi.org/ 10.3390 / cancers 13235898

Received: 28 October 2021 Accepted: 17 November 2021 Published: 24 November 2021

Publisher's Note: MDPI stays neutral with regard to jurisdictional claims in published maps and institutional affiliations.

Copyright: (c) 2021 by the authors. Licensee MDPI, Basel, Switzerland. This article is an open access article distributed under the terms and conditions of the Creative Commons Attribution (CC BY) license (https:// creativecommons.org/licenses/by/ $4.0 /)$.
Simple Summary: The clinical management for aggressive meningiomas remains challenging due to the lack of systemic treatment options. Receptor tyrosine kinases (RTKs) are frequently overexpressed in meningiomas and are associated with poor patient survival. In this study, we evaluated the clinically approved pan-RTK inhibitor ponatinib as a novel candidate for the treatment of aggressive meningiomas. Ponatinib decreased cell viability and proliferation of meningioma cells and subsequently induced programmed cell death. Furthermore, the drug demonstrated a considerable tumor growth inhibition without causing any adverse effects in mice. Mechanistically, this was presumably caused by blocking the PDGFR signaling pathway accompanied by induction of mitochondrial dysfunction. Altogether, the multi-RTKi ponatinib may serve as a promising candidate for targeted therapy for aggressive meningiomas.

Abstract: To date, there is no standard-of-care systemic therapy for the treatment of aggressive meningiomas. Receptor tyrosine kinases (RTK) are frequently expressed in aggressive meningiomas and are associated with poor survival. Ponatinib is a FDA- and EMA-approved RTK inhibitor and its efficacy in meningioma has not been studied so far. Therefore, we investigated ponatinib as a potential drug candidate against meningioma. Cell viability and cell proliferation of ponatinibtreated meningioma cells were assessed using crystal violet assay, manual counting and BrdU assay. Treated meningioma cell lines were subjected to flow cytometry to evaluate the effects on cell cycle and apoptosis. Meningioma-bearing mice were treated with ponatinib to examine antitumor effects in vivo. qPCR was performed to assess the mRNA levels of tyrosine kinase receptors after ponatinib treatment. Full-length cDNA sequencing was carried out to assess differential gene expression. IC50 values of ponatinib were between 171.2 and $341.9 \mathrm{nM}$ in three meningioma cell lines. Ponatinib induced G0/G1 cell cycle arrest and subsequently led to an accumulation of cells in the subG1-phase. A significant induction of apoptosis was observed in vitro. In vivo, ponatinib inhibited meningioma growth by $72.6 \%$. Mechanistically, this was associated with downregulation of PDGFRA/B and FLT3 mRNA levels, and mitochondrial dysfunction. Taken together, ponatinib is a promising candidate for targeted therapy in the treatment of aggressive meningioma. 
Keywords: meningioma; ponatinib; RTKi; NCH93; PDGFRA; PDGFRB; mitochondrial dysfunction

\section{Introduction}

Meningioma (MGM) is the most frequent primary brain tumor, accounting for $38.3 \%$ of primary brain tumors overall reported in the United States between 2013 and 2017 [1]. Approximately $80 \%$ of MGMs are classified into World Health Organization (WHO) grade I (benign), $15-20 \%$ in WHO grade II (atypical), and $1-4 \%$ in grade III (malignant) meningiomas [1]. The majority of MGMs display an indolent clinical course, with a $5-10 \%$ recurrence rate at 5 years [1]. However, high-grade MGMs are associated with a higher recurrence rate and poor prognosis [1]. In recent studies, median survival for malignant MGM was 53 months while 10-year survival was only $23 \%$ to $59.6 \%$ [1,2]. The mainstay of therapy consists of surgical removal of the tumor and/or radiotherapy. However, there is currently no effective systemic treatment available for the treatment of aggressive meningiomas $[3,4]$.

Establishing novel drug-based therapies for meningiomas is essentially based on the understanding of key molecular drivers for meningioma growth and tumor invasion. In the recent decade, several frequent genetic alterations were discovered, which led to the subsequent initiation of clinical studies (NCT02523014; NCT03071874) [5-9]. However, mutated targets are mainly found in non-NF2 benign meningiomas [5,7]. Several studies have demonstrated that key signaling pathways such as phosphoinositide 3-kinase (PI3K) and mitogen-activated protein kinase (MAPK) are activated in both benign and higher grade meningiomas [10-13]. These signaling pathways are activated by the receptor tyrosine kinase family (RTKs), such as epidermal growth factor receptor (EGFR), fibroblast growth factor receptor (FGFR), platelet-derived growth factor receptor (PDGFR), vascular endothelial growth factor receptor (VEGFR), or insulin-like growth factor receptor (IGFR) [13]. Moreover, expression of VEGFR, PDGFR, and EGFR is associated with high-grade MGMs and shorter progression-free survival (PFS) [14-16]. Therefore, targeting RTKs using tyrosine kinase inhibitors (TKis) emerged as a promising approach for the treatment of MGMs [17]. Previously, several studies investigated anti-meningioma effects of TKis [18-20]. Despite a previous preclinical analysis of regorafenib and sorafenib showed antitumor activity in vitro [19], results from clinical trials of TKi-treated meningioma showed no to only a moderate response. For example, a phase II trial of another TKi, imatinib, showed $0 \%$ of 6-month progression-free survival (6M PFS) for atypical and malignant MGMs [18]. In addition, EGFRi erlotinib and gefitinib resulted in $29 \%$ of $6 \mathrm{M}$ PFS without any objective imaging responses for the treatment of atypical and malignant MGMs in a recent phase II trial [20]. One possible explanation of the rather modest clinical activity of TKis might be drug resistance via bypass activation of other RTKs ensuring constant activation of the downstream signaling [21]. This mechanism is currently best understood in lung cancer [21]. Therefore, TKis with high affinity to multiple RTKs may be a promising approach for targeted therapy of high-grade MGMs. Sunitinib inhibiting PDGFR, VEGFR, and KIT is such an example. The drug has been evaluated in a phase II clinical trial with a $6 \mathrm{M}$ PFS of $42 \%$ in recurrent and progressive atypical and anaplastic MGMs [22,23]. Although results were promising, the small sample size and a considerable toxicity to sunitinib were major limitations of this study [23].

Mitochondria are intracellular double-layer organelles generating more than $95 \%$ of energy in both normal and cancer cells [24]. Therefore, dysfunction of mitochondria by any cause may induce apoptosis and/or necrosis [25]. Interestingly, several studies reported that TKis may disrupt the normal function of mitochondria in cancer by promoting reactive oxygen species (ROS) generation, and inducing mitochondrial fragmentation, mitophagy, and release of cytochrome c $[25,26]$. Furthermore, TKi-induced mitochondrial dysfunction is also associated with several adverse effects including diarrhea, fatigue, and hypertension [27]. Ponatinib is a FDA- and EMA-approved TKi for patients suffering 
from imatinib-resistant chronic myeloid leukemia (CML) and Philadelphia chromosomepositive $(\mathrm{Ph}+)$ acute lymphoblastic leukemia [28]. Beside its potent inhibition of fusion gene Bcr-Abl, ponatinib also inhibits multiple other RTKs, including PDGFR, VEGFR1 and 2, FGFR1-4, RET, c-KIT, and FMS-like tyrosine kinase 3 (FLT3) [29-32]. Moreover, ponatinib demonstrated potent antitumor activity in preclinical models of a variety of human cancers, including rhabdomyosarcoma, thyroid cancer, lung cancer, gastrointestinal stromal tumors, glioblastoma, and endometrial cancer [29,33-37]. In this study, we evaluated the efficacy of the ponatinib in MGM cells and found that ponatinib demonstrated potent anti-meningioma effects in vitro and in vivo presumably through PDGFRA/B inhibition and mitochondrial dysfunction.

\section{Materials and Methods}

\subsection{Cell Culture}

The benign cell line Ben-Men-1 (Leibniz Institute DSMZ, Braunschweig, Germany), the anaplastic meningioma cell line NCH93 [10] and IOMM-Lee were cultured in Dulbecco's Modified Eagle Medium (DMEM, Life Technologies Limited, Paisley, UK) supplemented with 10\% fetal bovine serum superior (Sigma-Aldrich, St. Louis, MO, USA), 2\% GlutaMAX ${ }^{\mathrm{TM}}$-I (100X, Life Technologies Corporation, Grand Island, NY, USA), and 1\% Penicillin/Streptomycin (Life Technologies Corporation, Grand Island, NY, USA) at $37{ }^{\circ} \mathrm{C}$ in a humidified environment with $5 \% \mathrm{CO}_{2}$ atmosphere. Mycoplasma contamination was excluded by $4^{\prime}$,6-diamidino-2-phenylindole staining (DAPI, Life Technologies Corporation, Eugene, OR, USA). NCH93 cell line was authenticated by STR DNA profiling analysis (Leibniz Institute DSMZ, Braunschweig, Germany).

\subsection{Crystal Violet Assay}

Cells were seeded at a density of 5000 cells / well in a 96-well plate with $200 \mu \mathrm{L}$ medium. On the next day, cells were treated with ponatinib (MedChemExpress, Monmouth Junction, NJ, USA) in 9 concentrations ranging from 1 to $5000 \mathrm{nM}$ and incubated for $48 \mathrm{~h}$. Then, medium was removed, and cells were washed with $100 \mu \mathrm{L}$ Dulbecco's Phosphate Buffered Saline (DPBS, Life Technologies Limited, Paisley, UK) once. Subsequently, $50 \mu \mathrm{L}$ of $0.5 \%$ crystal violet (Sigma-Aldrich, St. Louis, MO, USA) was added into wells and cells were incubated for $15 \mathrm{~min}$ at room temperature (RT) on a shaker. Next, crystal violet was removed and cells were washed with Aqua (B.Braun, Melsungen, Germany). Plates were left to dry overnight in a fume hood. On the following day, $200 \mu \mathrm{L}$ of methanol (Carl Roth $\mathrm{GmbH}$, Karlsruhe, Germany) was added to dissolve crystal violet. The optical density was recorded at $555 \mathrm{~nm}$ using a microplate reader (Infinite F200 pro, Tecan GmbH, Grödig, Austria). IC50 values were calculated by nonlinear regression in GraphPad Prism (version 9.0.0, GraphPad, San Diego, CA, USA).

\subsection{Growth Curves}

A total of $1 \times 10^{5}$ cells of Ben-Men- 1 and IOMM-Lee, and $5 \times 10^{5}$ cells of NCH93 were seeded in 6-well plates. The next day, cells were treated with DMSO control or ponatinib at IC50 and $10 \times$ IC50. Single cell suspensions were harvested at 0,24 , and $48 \mathrm{~h}$ after treatment, and manually counted using a Neubauer chamber (Reichert, Buffalo, NY, USA). Data were normalized to the DMSO control group.

\subsection{BrdU Assay}

Cell proliferation was measured using the Cell Proliferation ELISA, BrdU Kit (Roche Diagnostics GmbH, Mannheim, Germany). NCH93, Ben-Men-1, and IOMM-Lee were seeded in 96-well plates at a density of 4000 cells/well. Cells were treated with ponatinib at $5 \times$ IC50. On days 1,2, and 3, $10 \mu \mathrm{L}$ BrdU labeling solution was added to the cells at a final concentration of $10 \mu \mathrm{M}$ and incubated for $2 \mathrm{~h}$. Next, the medium was removed from the cells by tapping off. Cells were fixed with $200 \mu \mathrm{L}$ per well FixDenat and incubated for an additional $30 \mathrm{~min}$ at RT. FixDenat was removed and $100 \mu \mathrm{L}$ anti-BrdU-POD working 
solution per well was added and incubated for $90 \mathrm{~min}$ at RT. The antibody conjugate was removed, and wells were rinsed 3 times with $200 \mu \mathrm{L}$ PBS. Thereafter, $100 \mu \mathrm{L}$ substrate solution was added and incubated for an additional $10 \mathrm{~min}$ at RT. Then, absorbance was measured at $450 \mathrm{~nm}$ and reference wavelength $690 \mathrm{~nm}$ by a microplate reader (Infinite F200 pro, Tecan GmbH, Grödig, Austria).

\subsection{Wound Healing Assay}

A total of $8 \times 10^{5}$ cells from each cell line were seeded in 6-well plates. After reaching $100 \%$ confluency, a straight gap was generated on the cell monolayer using a $100 \mu \mathrm{L}$ pipette tip. Then, the cell monolayer was washed carefully with $1 \mathrm{~mL}$ DPBS to remove cell debris and thereafter $2 \mathrm{~mL}$ fresh medium was added. Ponatinib was added at the concentration of IC50. DMSO was used as control (Sigma-Aldrich, St. Louis, MO, USA). Images of the gap were taken at 0 and $12 \mathrm{~h}$. Migrated areas of cells were calculated by ImageJ (version1.8.0, National Institutes of Health, Bethesda, MD, USA). The areas covered by migrating ponatinib-treated cells were normalized to the mean of the DMSO-treated group.

\subsection{Cell Cycle Analysis}

A total of $3 \times 10^{5}$ cells were seeded in 6-well plates. On the next day, cells were treated with ponatinib at $10 \times$ IC50 or DMSO control (Sigma-Aldrich, St. Louis, MO, USA) for 24, 48 , and $72 \mathrm{~h}$. At each time point, cells were harvested and fixed with $85 \%$ ice-cold ethanol (Carl Roth $\mathrm{GmbH}$, Karlsruhe, Germany). After incubation for $30 \mathrm{~min}$ at $4{ }^{\circ} \mathrm{C}$, cells were centrifuged at $300 \times g$ for $5 \mathrm{~min}$ at $4{ }^{\circ} \mathrm{C}$ and ethanol was carefully removed. Cells were then washed with $1 \mathrm{~mL}$ ice-cold DPBS twice. Thereafter, cells were resuspended in $500 \mu \mathrm{L}$ DPBS and $5 \mu \mathrm{L}$ RNAse A (Lucigen, Middleton, WI, USA) was added to the cells and incubated for $30 \mathrm{~min}$ at $4^{\circ} \mathrm{C}$. Prior to measurement, $1 \mu \mathrm{L}$ propidium iodide (PI) (Sigma-Aldrich, St. Louis, MO, USA) was added at a final concentration of $50 \mu \mathrm{g} / \mathrm{mL}$. Cells were analyzed by LSR II flow cytometer (BD Biosciences, San Jose, CA, USA) and cell cycle distribution was analyzed using the software FlowJo (version 10.6.1, FlowJo LLC, Ashland, OR, USA).

\subsection{Apoptosis Assay}

A total of $3 \times 10^{5}$ cells were seeded in 6-well plates. On the following day, cells were treated with ponatinib at $10 \times$ IC50 or DMSO control (Sigma-Aldrich, St. Louis, MO, USA) for 24,48 , and $72 \mathrm{~h}$, respectively. At each time point, cells were collected from each well and transferred into a $15 \mathrm{~mL}$ Falcon tube (Corning Science Mexico SA de CV, Tamaulipas, Mexico). Subsequently, cells were centrifuged at $300 \times g$ for $5 \mathrm{~min}$ at $4{ }^{\circ} \mathrm{C}$. Then, the supernatant was carefully discarded and the cell pellets were resuspended and washed twice with $1 \mathrm{~mL}$ ice-cold DPBS. Thereafter, cells were washed with $1 \mathrm{~mL} 1 \times$ annexin V binding buffer. After centrifugation, the supernatant was removed and the cell pellet was resuspended with $100 \mu \mathrm{L} 1 \times$ annexin V binding buffer. Finally, cells were stained with $2 \mu \mathrm{L}$ annexin V FITC antibody (Biolegend, San Diego, CA, USA) and $50 \mu \mathrm{g} / \mathrm{mL}$ PI and incubated for $15 \mathrm{~min}$ in the dark at $4{ }^{\circ} \mathrm{C}$. Before detection, $1 \times$ annexin $\mathrm{V}$ binding buffer was added to the cells to a total volume of $500 \mu \mathrm{L}$. Cells were then measured by flow cytometry within $1 \mathrm{~h}$ and analyzed using the software FlowJo (version 10.6.1, FlowJo LLC, Ashland, OR, USA).

\subsection{Meningioma Xenograft Experiments}

All experiments were done in accordance with the regulations of animal protection and approved by the Regierungspraesidium Karlsruhe, Germany. Five to six-week-old female NMRI/nu mice (Janvier Laboratory, Le Genest-Saint-Isle, France) received subcutaneous injections into the right flank with $4 \times 10^{6} \mathrm{NCH} 93$ cells in $100 \mu \mathrm{L}$ medium and $100 \mu \mathrm{L}$ Matrigel (Corning, San Diego, CA, USA). Tumor volume was measured daily by using a digital caliper and it was calculated using the following equation: Volume $=$ (Length $\times$ Width $^{2}$ )/2 [38], where length represents the longest tumor diameter and width represents the perpendicular tumor diameter. When the tumor volume reached $200 \mathrm{~mm}^{3}$, mice were 
randomly divided into DMSO and ponatinib treatment groups. The dosage of $10 \mathrm{mg}$ per $\mathrm{kg}$ bodyweight of ponatinib was administered intraperitoneally daily. The weight of the mice was measured on a daily basis. On day 21, mice were sacrificed, and blood was drawn and immediately sent to the central laboratory of University Hospital Heidelberg for further analysis. Excised tumors were weighed and photographed. Tumor tissues were snap-frozen and stored at $-80{ }^{\circ} \mathrm{C}$ until further processing.

\subsection{Immunohistochemical Staining}

Acetone-fixed cryosection slides were prepared. Slides were incubated with rabbit polyclonal anti-Ki-67 (1:50 dilution, ab15580, Abcam, Cambridge, UK), cleaved caspase-3 (1:400 dilution, 9661, Cell Signaling, Danvers, MA, USA) antibodies diluted with DAKO diluent (Agilent Technologies, Santa Clara, CA, USA) for $60 \mathrm{~min}$ at RT, and washed three times with PBS-Tween-20 (0.05\%) (Sigma-Aldrich, St. Louis, MO, USA). Next, secondary antibody (anti-rabbit, Vector, Burlingame, CA, USA) diluted in goat serum (Vector, Burlingame, CA, USA) and DPBS was applied to the slides and incubated for $30 \mathrm{~min}$. After washing steps as described above, an avidin-biotin-complex (Vector, Burlingame, CA, USA) was added to the slides for 30 min incubation. Then, the AEC substrate (Vector, Burlingame, CA, USA) was applied to the slides and incubated for 3 min (anti-Ki-67) or $8 \mathrm{~min}$ (cleaved caspase-3). Finally, slides were counterstained with hematoxylin (Carl Roth $\mathrm{GmbH}$, Karlsruhe, Germany) for $7 \mathrm{~min}$. Ki-67 and cleaved caspase-3 positive cells were counted in ten high-power fields per slide. Rabbit IgGs (ab37415, Abcam, Cambridge, UK) served as a negative control.

\subsection{Quantitative Real-Time PCR}

Total RNA was extracted from eight xenograft tumor samples (four from the ponatinibtreated group and four from the DMSO-treated group) using the RNeasy Mini Kit (Qiagen, Valencia, CA, USA) according to the manufacturer's instructions. RNA was quantified by NanoDrop ND-1000 spectrophotometer (Thermo-Scientific, Waltham, MA, USA). Equal amounts of total RNA $(1 \mu \mathrm{g})$ were reverse-transcribed using the Transcriptor First Strand cDNA Synthesis Kit (Roche, Basel, Switzerland) with random hexamer primers for $1 \mathrm{~h}$ at $50{ }^{\circ} \mathrm{C}$. qPCR was performed in quadruplicates on a LightCycler 480 (Roche, Basel, Switzerland) using the LightCycler 480 Probes Master and probes from the Universal Probe Library (Roche, Basel, Switzerland) as described (www.roche-applied-science.com). (last accessed on 5 February 2021). Relative fold changes between the expression of target genes were calculated by using the $2^{-\triangle \Delta C q}$ method. GAPDH, ACTB, and HPRT1 were used as reference genes. Relative expression mRNA levels of RTKs: FLT3, FGFR1, FGFR2, FGFR4, PDGFRA, PDGFRB, VEGFR1, and VEGFR2 were normalized to the mean of the DMSO tumor samples. The primers used are listed in Table S1.

\subsection{Full-Length cDNA Nanopore Sequencing}

Fifty ng of total RNA from two ponatinib-treated and two control tumors were reverse transcribed and barcoded using the SQK-PCB109 kit (Oxford Nanopore Technology, Oxford, UK). Samples were run on a MinION R9.4.1 flowcell (Oxford Nanopore Technology, Oxford, UK). Base calling and demultiplexing were performed using Guppy 4.5.4. Filtered reads (minimum average Phred score 7 ) were aligned to a combined human and mouse genome (GRCh38.p13 and GRCm39) using minimap2 2.18, whereof only human gene (GENCODE.v37) alignments with a quality score more than 20 were counted using featureCounts 2.0.0. Differential gene expression analysis was performed using the package DESeq2 in the software R (v.4.1.0). Differentially expressed genes were determined based on a false discovery rate (FDR) cutoff of $p<0.05$ and $\log 2$ fold change $\geq 1$ or $\leq-1$. 


\subsection{Analysis of Mitochondrial Dysfunction}

In order to explore functional differences between xenograft tumors, gene set enrichment analysis (GSEA) was performed using the packages clusterProfiler and enrichplot in the software R (v.4.1.0). For the identification of genes associated with mitochondrial dysfunction, differentially expressed genes were analyzed by GSEA using Gene Ontology (GO) gene sets accessed from MSigDB [39].

\subsection{Statistical Analysis}

All in vitro experiments were performed at least in triplicates and were independently repeated three times, and results were expressed as mean \pm SEM. $p$-values were calculated using a two-tailed Student's t-test in GraphPad (version 9.0.0, GraphPad, San Diego, CA, USA). $p$-values $<0.05$ were considered significant $\left({ }^{*} p<0.05 ;{ }^{* *} p<0.01 ; * * * 00.001\right)$.

\section{Results}

\subsection{Ponatinib Decreased Viability and Proliferation of Meningioma Cells}

To investigate the efficacy of ponatinib for the treatment of meningioma, we assessed the half-maximal inhibitory concentration (IC50) of ponatinib using crystal violet assay in the anaplastic MGM cell lines IOMM-Lee, NCH93, and the benign MGM cell line Ben-Men1 (Figure 1A). IC50 values of ponatinib ranged from 171.2 to $341.9 \mathrm{nM}$ in all MGM cell lines, whereas IOMM-Lee presented with the lowest IC50 value of $171.2 \mathrm{nM}$ (95\% confidence interval: 147.2-199.0). Furthermore, the IC50 values of ponatinib in NCH93 and BenMen-1 were $206.7 \mathrm{nM}$ (185.1-230.8) and $341.9 \mathrm{nM}$ (250.1-467.5), respectively. To assess cell growth over time, cells were treated with ponatinib at IC50 and $10 \times$ IC50 and the number of cells were counted manually. After $48 \mathrm{~h}$ treatment, the number of cells significantly decreased to $42.3 \%, 47.7 \%$, and $51.6 \%$ compared to control in IOMM-Lee, NCH93, and Ben-Men-1, respectively (Figure 1B, $p<0.01$ ). As expected, an even stronger inhibitory effect was observed when cells were treated with $10 \times$ IC50 of ponatinib. The number of cells declined to $25.5 \%, 17.4 \%$, and $19.2 \%$ compared to DMSO treatment, respectively $(p<0.001)$. To validate the effect of ponatinib on cell proliferation, we performed BrdU assay and treated cells with $5 \times$ IC50 of ponatinib. Strikingly, incorporation of BrdU in ponatinib-treated cells was less than $0.4 \%$ compared to the control group in all cell lines after $24 \mathrm{~h}$ and continued until $72 \mathrm{~h}$ treatment $(p<0.001$, Figure S1A). Collectively, ponatinib exhibited a strong antiproliferative effect on meningioma cell lines at the nanomolar level. 
A

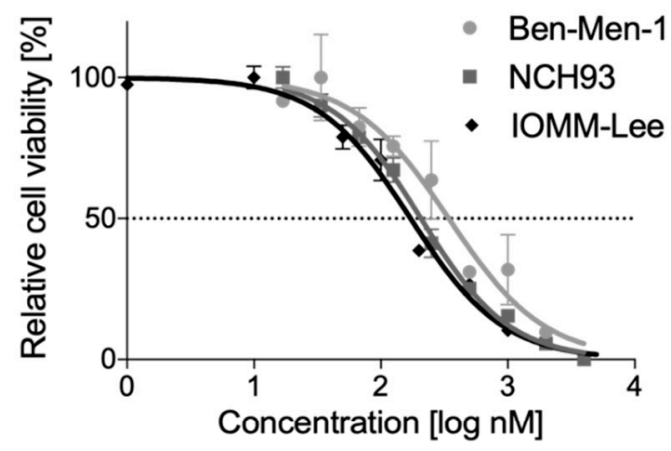

Ponatinib:

B

Ben-Men-1

$\mathrm{NCH} 93$
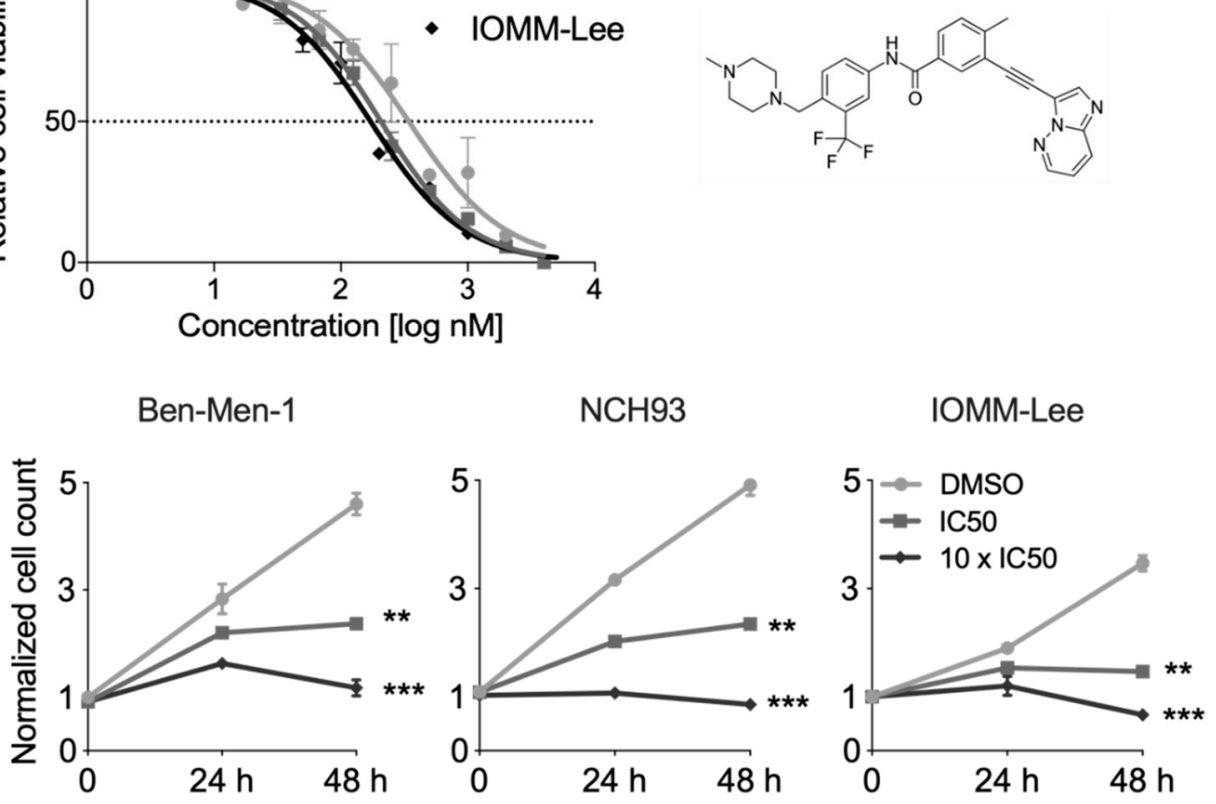

C
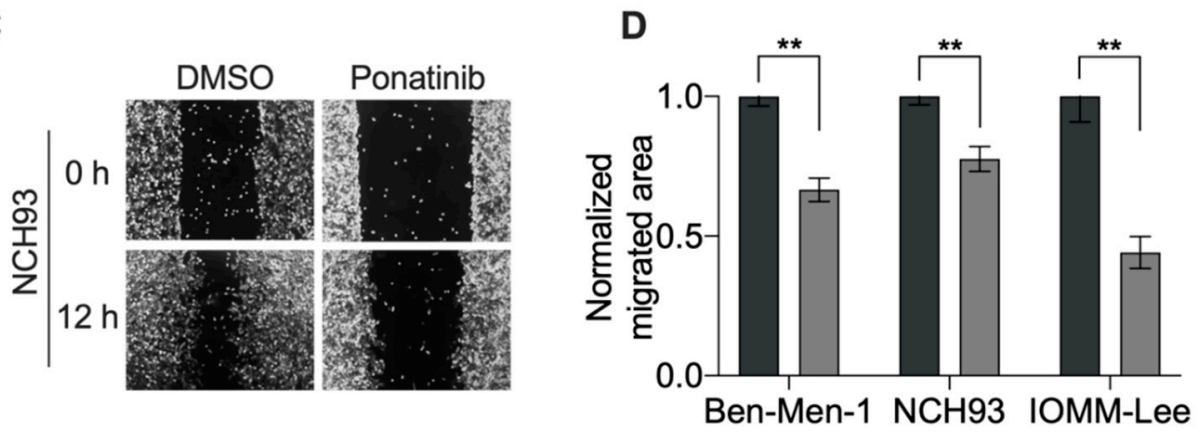

Figure 1. Ponatinib reduced meningioma cell proliferation and migration: (A) Illustrated are dosecurves of ponatinib in the benign meningioma cell line Ben-Men-1, and the malignant cell lines NCH93 and IOMM-Lee (left). The molecular structure of ponatinib is depicted (right). (B) Cells were treated with increasing concentrations (IC50 and $10 \times$ IC50) of ponatinib or DMSO followed by a manual counting at $0 \mathrm{~h}, 24 \mathrm{~h}$, and $48 \mathrm{~h}$. (C) Wound healing assay using NCH93 cells showed delayed closure of the wound gap upon ponatinib treatment. (D) Quantification of the extent of the wound closure after $12 \mathrm{~h}$. Each experiment was performed in triplicate and repeated three times. Results are expressed as mean \pm SEM. ${ }^{* *} p<0.01 ; * * * 00.001$.

\subsection{Ponatinib Reduced Migration of Meningioma Cells}

To investigate the anti-migratory effect of ponatinib in meningioma cells, a wound healing assay was performed (Figure 1C). Twelve hours after treatment, the area covered by migrating cells was reduced by $55.8 \%$ in IOMM-Lee cells ( $p=0.007$, Figure 1D). To a lesser degree, treated NCH93 and Ben-Men-1 cells demonstrated a reduction of the area covered by migrating cells by $22.4 \%$ and $33.5 \%$, respectively ( $p=0.014$ and $p=0.003$, Figure 1D). These findings suggested that ponatinib is able to affect cell migration of benign and malignant meningioma cells. 


\subsection{Accumulation of Cells in G0/G1 and subG1-Phase upon Treatment}

Next, we were interested in the effects of ponatinib on the cell cycle in meningioma cells. Therefore, ponatinib-treated cells were analyzed by flow cytometry (Figure 2A). Ponatinib induced meningioma cell cycle arrest in G0/G1-phase and subsequently increased the number of cells in the subG1-phase. After $24 \mathrm{~h}$ of treatment, the percentage of cells in the G0/G1-phase increased from $57.5-65.6 \%$ to $68-81.3 \%$ in all cell lines $(p<0.001$, Figure 2B). Simultaneously, the relative number of cells in subG1-phase increased over time. Remarkably, $75.1 \%$ of NCH93 cells were in the subG1-phase compared to $3.7 \%$ in vehicle control after $72 \mathrm{~h}$ treatment $(p<0.001$, Figure 2B). Furthermore, the proportion of cells in the subG1-phase also increased significantly to $44.8 \%$ and $30.0 \%$ in IOMM-Lee and Ben-Men-1 cells, respectively $(p<0.001$, Figure 2B). Taken together, these results suggest that ponatinib blocks G1 to S-transition and subsequently an accumulation of cells in subG1-phase.

A
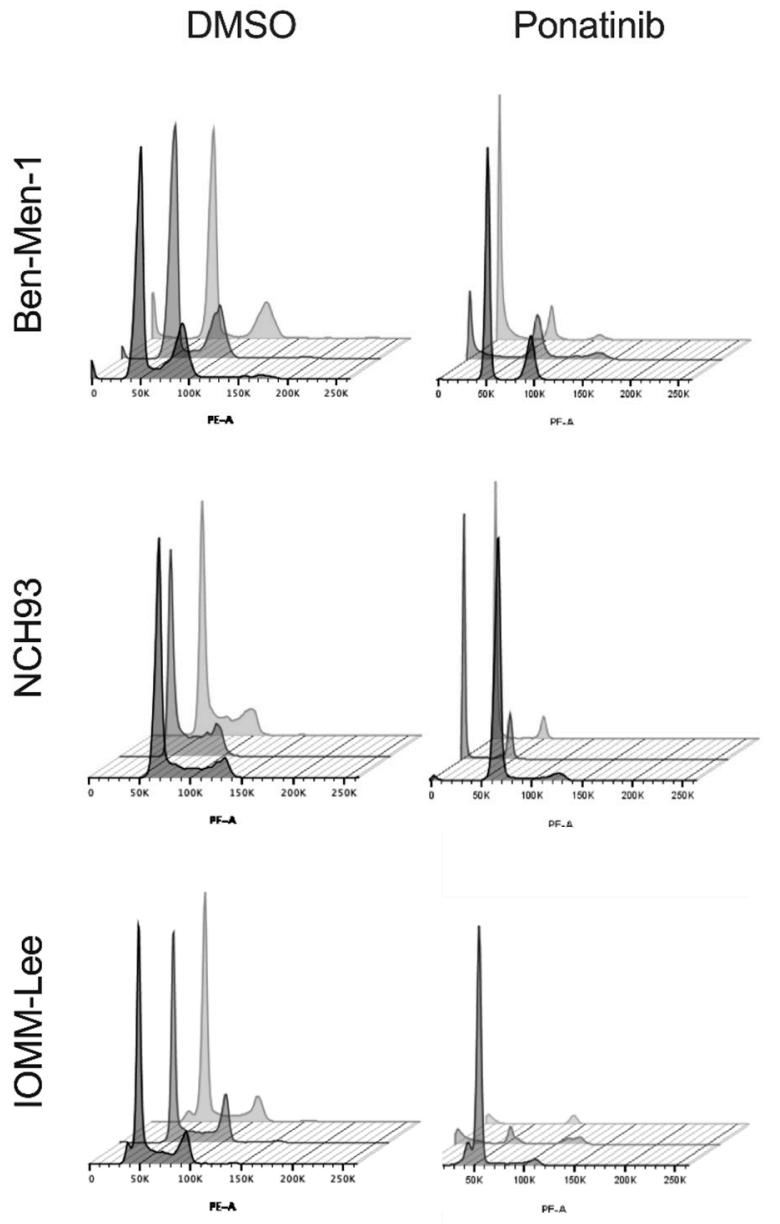

Ponatinib
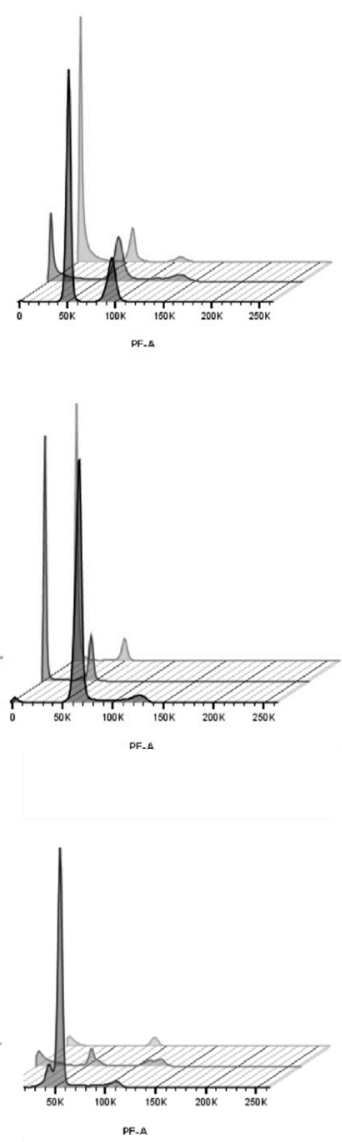

B

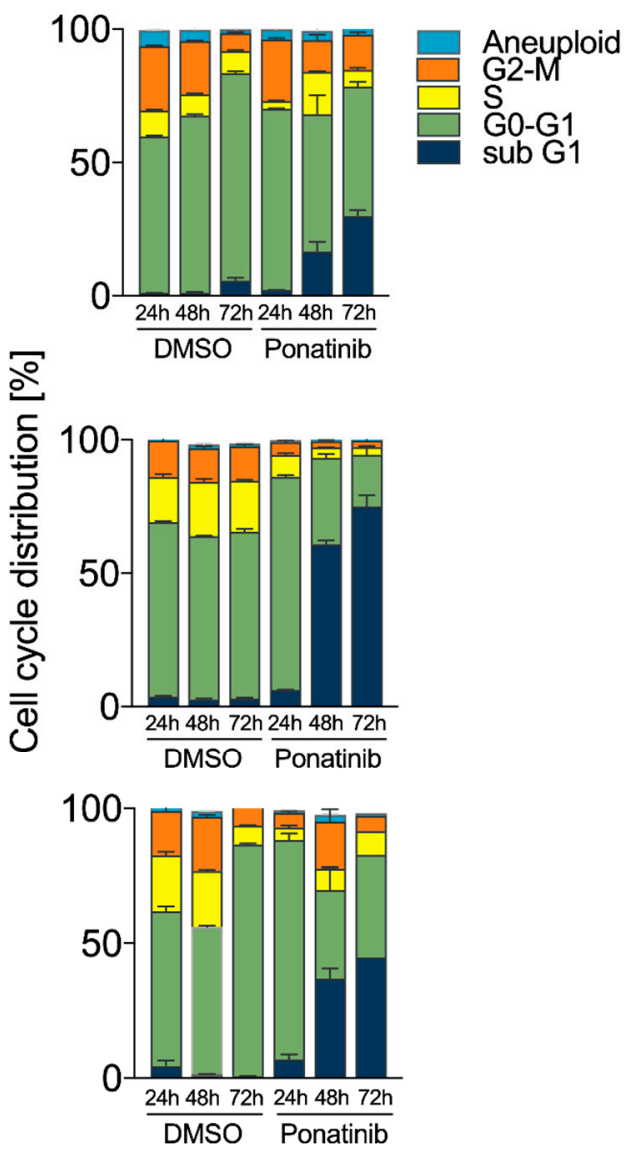

Figure 2. Ponatinib disrupts the meningioma cell cycle by induction of G0/1-arrest and subsequent accumulation of cells in subG1-phase: (A) Cell cycle distribution of meningioma cells treated with $10 \times$ IC50 of ponatinib or DMSO after 24, 48, and $72 \mathrm{~h}$. (B) Quantification of cell cycle distributions in meningioma cell lines. Each experiment was performed in triplicate and repeated three times. Results are expressed as mean \pm SEM.

\subsection{Ponatinib Effectively Induced Apoptosis of Meningioma Cells}

To test whether the increased proportion in subG1-phase upon ponatinib treatment is attributed to apoptosis, ponatinib-treated meningioma cells were stained with annexin $\mathrm{V} / \mathrm{PI}$ and analyzed by flow cytometry (Figure $3 \mathrm{~A}$ ). Ponatinib significantly induced apoptosis in all cell lines. In line with the previous cell cycle results, $83 \%$ of NCH93 cells underwent apoptosis after $72 \mathrm{~h}$ treatment with ponatinib $(p<0.001$, Figure 3B). Furthermore, ponatinib effectively induced apoptosis up to $37.5 \%$ and $17.5 \%$ in IOMM-Lee and 
Ben-Men-1, respectively $(p<0.001 ; p=0.0012)$. In summary, ponatinib-treatment leads to apoptosis in meningioma cells.

A
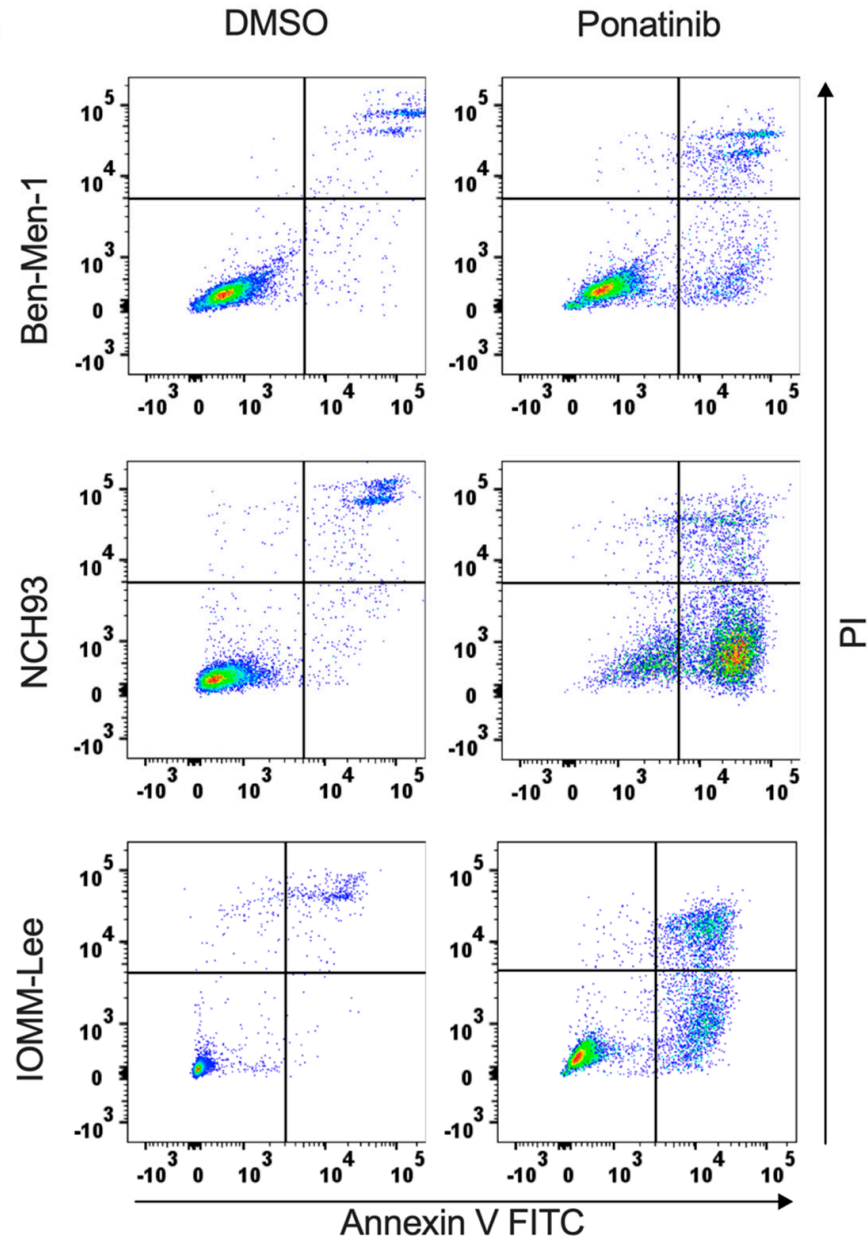

Ponatinib
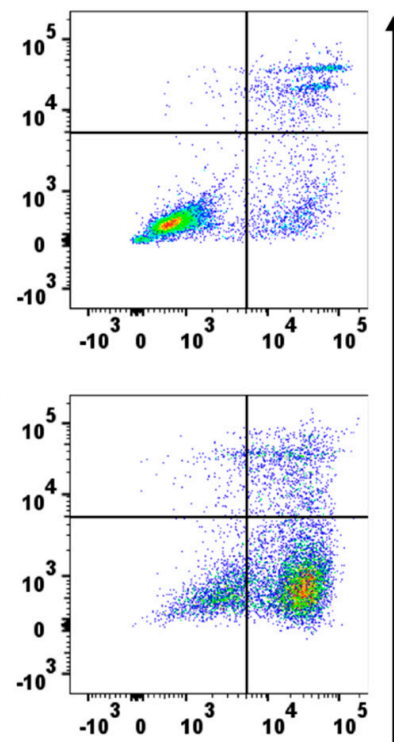

B
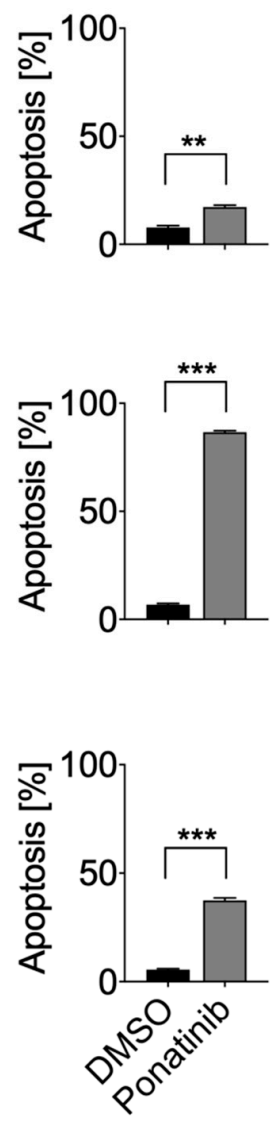

Figure 3. Ponatinib induced meningioma cell apoptosis: (A) Early- and late-stage apoptosis was induced after $72 \mathrm{~h}$ of treatment with $10 \times$ IC50 of ponatinib. (B) Percentage of apoptotic cells in ponatinib-treated or DMSO-treated meningioma cells. The experiment was performed in triplicate and independently repeated three times. Results are expressed as mean \pm SEM. ${ }^{* *} p<0.01$; *** $p<0.001$.

\subsection{RTKi Ponatinib Blocks Tumor Growth In Vivo}

To evaluate the efficacy of ponatinib in vivo, we implanted NCH93 cells in the flank of $\mathrm{NMRI} / \mathrm{nu}$ mice as described before [40,41]. After the tumor volume reached approximately $200 \mathrm{~mm}^{3}$, mice were randomized into ponatinib or DMSO control group. Mice were treated with $10 \mathrm{mg} / \mathrm{kg}$ bodyweight of ponatinib daily. On day 21, mice were sacrificed, weighted, drawn blood, and tumors were excised and weighted. Ponatinib potently inhibited meningioma tumor growth by $72.6 \%$ as compared to DMSO on day 21 ( $p<0.001$; Figure $4 \mathrm{~A}, \mathrm{~B}$ ). Similarly, excised tumor weights in the ponatinib-treated group were significantly lower than that in the control group ( $0.27 \mathrm{~g}$ vs. $0.94 \mathrm{~g}, p<0.001$, Figure S2A). The treatment had no impact on the body weight of the mice and resulted only in minor changes of blood parameters (Figure 4C,D). Only the mean corpuscular hemoglobin concentration (MCHC) was slightly affected, indicating that the applied treatment regime of ponatinib was well-tolerated in mice ( $p=0.43$, Figure $4 \mathrm{D})$. Furthermore, the excised tumors were stained for the proliferation marker Ki-67 and apoptosis marker cleaved caspase-3. The immunohistochemical staining confirmed decreased levels of Ki-67 upon ponatinib treatment (ponatinib: 38\%; DMSO: 52\%, $p=0.003$, Figure 4E). Interestingly, the expression of 
cleaved caspase- 3 was less than $0.1 \%$ in both control and treatment groups, suggesting a more pronounced inhibition of proliferation rather than induction of apoptosis in vivo (Figure S2B). Moreover, we were interested whether mRNA levels were affected upon ponatinib treatment. Therefore, RNA from frozen mouse tumor samples was isolated and qRT-PCR was performed (Figure 4F). The mRNA levels of PDGFRA and PDGFRB were significantly reduced by $83.8 \%$ and $38.6 \%$ in the ponatinib-treated group $(p=0.0037$ and $p=0.02$, respectively). In addition, the mRNA levels of FLT3 showed a nonsignificant reduction $(p=0.052)$. FGFR1, 2 , and $4 \mathrm{mRNA}$ levels were not altered upon ponatinib treatment. Interestingly, the mRNA levels of VEGFR1 and VEGFR2 were increased significantly upon ponatinib treatment, which might be a compensatory effect. Lastly, the expressions of FGFR3 mRNA were not detected in NCH93 xenografts. Taken together, ponatinib blocked meningioma tumor growth in vivo by decreased proliferation presumably through inhibition of PDGFR signaling pathway.

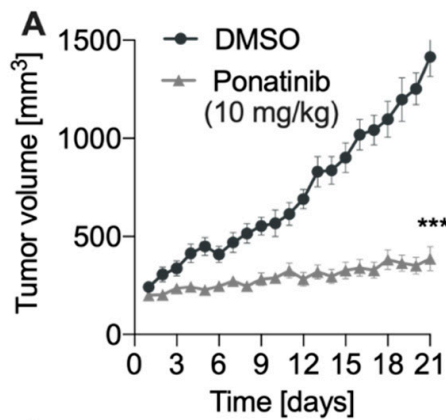

C

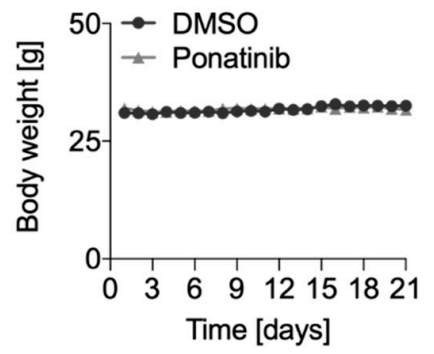

E

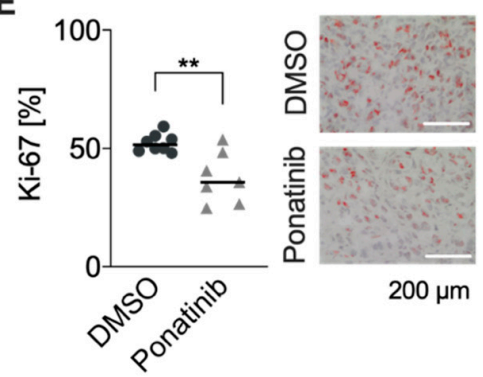

B

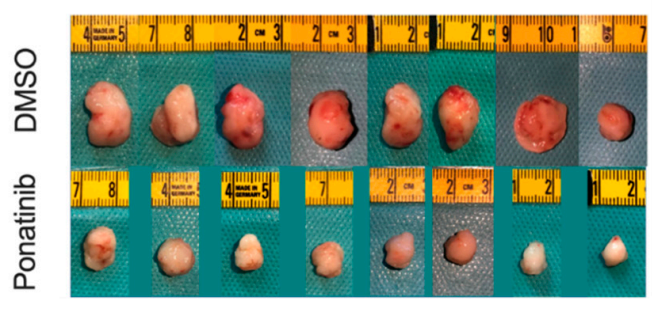

D

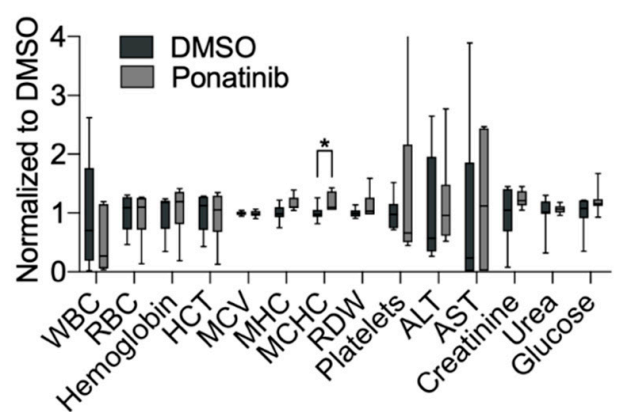

$\mathbf{F}$

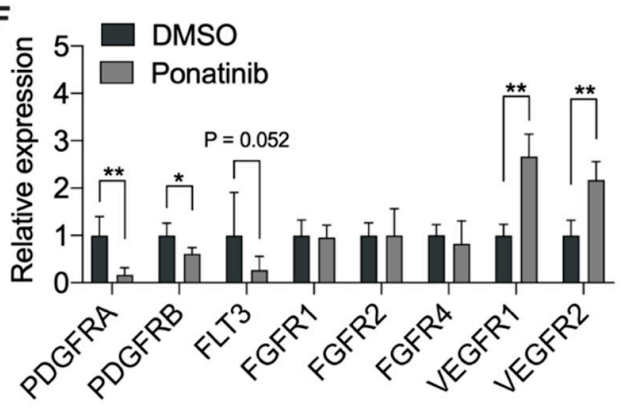

Figure 4. Ponatinib inhibited tumor growth in vivo: (A) NCH93 tumor-bearing were randomized into two groups after reaching a tumor size of $200 \mathrm{~mm}^{3}$. Mice were treated with ponatinib $(10 \mathrm{mg} / \mathrm{kg}$ body weight, i.p. daily) for 21 days. Ponatinib significantly inhibited NCH93 tumor growth in NMRI/nu mice. (B) On day 21, mice were sacrificed and tumors were excised. (C) Mice weight was not affected by the treatment. (D) Blood samples from the mice were drawn immediately after killing and were then analyzed. Hematological parameters remained unchanged except for a minor change in MCHC. (E) Ki-67 expression indicated a significant decrease in the proliferation of ponatinib-treated tumors (left). Representative images of Ki-67 stained tumor sections (right). Bar represents $200 \mu \mathrm{m}$. (F) mRNA levels of PDGFRA and PDGFRB were reduced and mRNA levels of VEGFR1 and VEGFR2 were increased upon ponatinib treatment. ${ }^{*} p<0.05 ; * * 0.01 ; * * * 00.001$. 


\subsection{Ponatinib Treatment Induced Mitochondrial Dysfunction}

To further explore the downstream effects of ponatinib treatment in meningioma, we performed full-length cDNA sequencing of ponatinib- versus DMSO-treated meningioma xenografts. By applying cutoff values of FDR $<0.05$ and $\log 2 \mathrm{FC} \geq 1$, we detected 80 differentially expressed genes, where 58 were downregulated and 22 upregulated (Table S2). Interestingly, a large proportion of the downregulated genes were mitochondrialrelated, including MT-ND1, MT-ND2, MT-ND4, MT-CYB, MT-RNR, MT-CO, and MT-ATP6 (Figure 5A). Most of these downregulated genes identified as members of the electron transport chain $[42,43]$. To query if mitochondria are functionally involved in the treatment response of ponatinib, we conducted gene set enrichment analysis. We discovered a significant negative enrichment of GO terms that are related to mitochondrial dysfunction $\left(p_{\text {adj }}<0.001, \mathrm{NES}=-2.506\right.$, Figure 5B). However, when looking for changes in the receptor tyrosine kinase signaling pathway by reactome analysis, we only observed a non-significant upregulation of the signaling pathway in response to treatment $\left(p_{\text {adj }}=0.07, \mathrm{NES}=1.77\right.$; Figure S3). Taken together, these findings suggest that ponatinib primarily impairs the mitochondrial function, which subsequently impedes tumor growth in vivo.

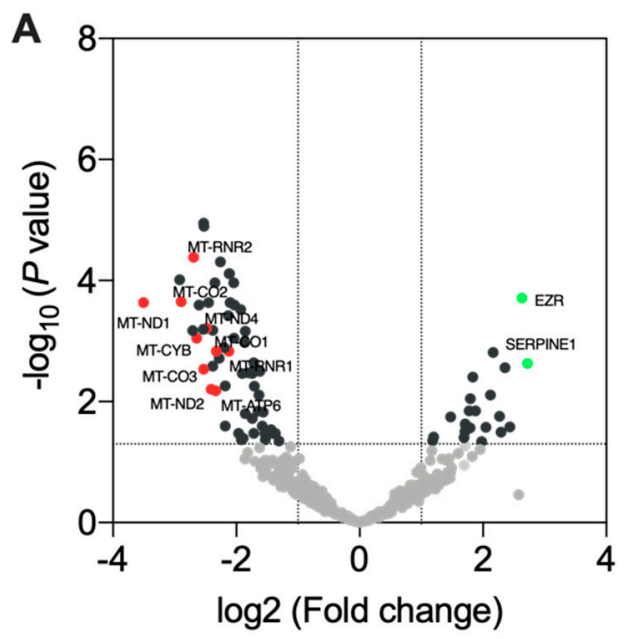

B

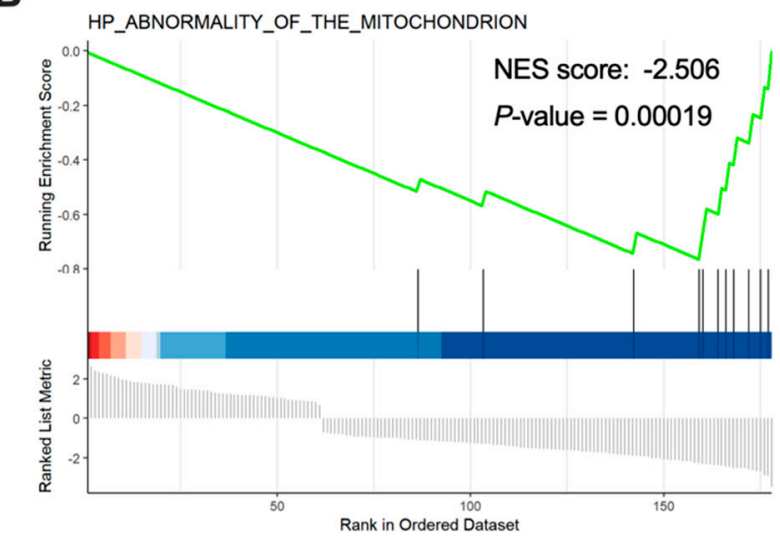

Figure 5. Ponatinib induced mitochondrial dysfunction: (A) Volcano plot of differentially expressed genes between ponatinib-treated and untreated meningiomas. Red dots: downregulated mitochondrial-related genes (log2 fold change $\leq$ $-1 ; F D R<0.05$ ). Green dots: upregulated genes (log2 fold change $\geq 1 ; F D R<0.05)$. (B) The results of gene set enrichment analysis (GESA) for GO gene sets.

\section{Discussion}

In this study, we explored the effects of the pan-TKi ponatinib on meningioma growth in vitro and in vivo. In three meningioma cell lines, proliferation was inhibited upon treatment, induced G0/G1-phase arrest and subsequently induced apoptosis. Moreover, ponatinib illustrated a significant tumor growth inhibition in vivo while being well-tolerated. Mechanistically, this was accompanied by RTK blockage of PDGFRA, PDGFRB, and FLT3. Furthermore, RNA-sequencing of the xenograft tumors revealed primarily deregulation of genes involved in the mitochondrial electron transport chain, suggesting mitochondrial dysfunction as an additional factor in impeding tumor growth upon ponatinib treatment.

When comparing the efficacy of ponatinib in meningioma cells to other tumor entities, its IC50 values are distributed in the lower end of the spectrum of all cancer types, ranging from 171.2 to $341.9 \mathrm{nM}$. Especially in solid tumors, reported IC50 values ranged from $20 \mathrm{nM}$ up to $6.1 \mu \mathrm{M}[30,31,35-37,44]$. Only in hematological malignancies did ponatinib exert a lower effective concentration in the range of 0.3 and $12.5 \mathrm{nM}$ [45]. Interestingly, when comparing IC50 values of different TKi in the same meningioma cell line, ponatinib's IC50 value is almost 10 and 50 times lower than the corresponding IC50s of TKis regorafenib and sorafenib ( $0.17 \mu \mathrm{M}$ vs. 1.5 and $7.5 \mu \mathrm{M}$, respectively) [19]. Similarly, the IC50 values of 
sunitinib were an order of magnitude higher in Ben-Men-1 and IOMM-Lee compared to ponatinib in the respective cell lines [22]. These findings indicate that ponatinib might be particularly promising for the treatment of meningioma.

To evaluate the impact of ponatinib on the cell cycle, we performed flow cytometry and annexin $\mathrm{V}$ staining. We found that ponatinib induced a robust G0/G1-cell cycle arrest in meningioma cells. Similar effects were reported in schwann cells and liver cancer cells $[46,47]$. While short-term treatment with ponatinib led to cytostasis, prolonged treatment resulted in cell death. We also observed ponatinib-induced apoptosis by accumulation of cells in subG1, which was confirmed by annexin V/PI staining. The rate of apoptosis after $72 \mathrm{~h}$ ponatinib treatment ranged from $17.5 \%$ to $83.0 \%$. Similar results were also observed in rhabdomyosarcoma cells when measuring the caspase $3 / 7$ activity [34]. Furthermore, ponatinib-treated glioblastoma U87MG cells display over $80 \%$ of condensed or fragmented nuclei upon ponatinib treatment, indicating apoptosis [36]. Collectively, these data demonstrate that ponatinib disrupts the cell cycle of meningioma cells and subsequently induces apoptosis.

To test the efficacy of ponatinib in vivo, we treated NCH93-bearing mice with a ponatinib dose of $10 \mathrm{mg} / \mathrm{kg}$ bodyweight daily. For the treatment of CML, the recommended starting dose of ponatinib is $45 \mathrm{mg}$ daily [28]. Dose conversion from human to animal results in dosages of approximately $9 \mathrm{mg} / \mathrm{kg}$ body weight in mice [48]. A similar treatment regime of $10 \mathrm{mg} / \mathrm{kg}$ body weight was used by other groups [34,44,49]. The treatment resulted in significantly reduced tumor growth by $72.6 \%$ in tumor volume and $71.3 \%$ in tumor weight after 21 days. These anti-tumor effects were comparable to that of ponatinibtreated endometrial cancer xenografts, reporting a growth inhibition of $49 \%$ in mice treated with the same dose of $10 \mathrm{mg} / \mathrm{kg}$ [49]. In addition, Whittle et al. and Li et al. reported a significant reduction of tumor growth in neuroblastoma and rhabdomyosarcoma, respectively [34,44]. In addition, the proliferation rate of tumors was measured by Ki-67 staining, which showed a reduction by $14 \%$ after ponatinib treatment. Interestingly, cleaved caspase- 3 staining showed less than $0.1 \%$ of apoptosis in both ponatinib-treated and control tumors, indicating that reduction in xenograft tumor growth was primarily based on a decreased proliferation. Although the heterotopic meningioma xenograft model is a well-established system to test the efficacy of drugs in mice [50], it may not entirely mirror the exact physiological tumor microenvironment and thus may induce unwanted changes in terms of proliferation, drug resistance, migration, and tumor evolution [51].

When examining the molecular targets of ponatinib in the xenograft tumors, we observed a significant reduction in mRNA levels of PDGFRA/B and FLT3 upon treatment. As described from several studies, PDGF and its receptor expressed abundantly on meningioma cells $[15,52]$. Specifically, the positive rate and the immunostaining intensity of $P D G F B$ and $P D G F B$ receptor were higher in atypical meningiomas than in benign ones [52]. Importantly, PDGF has been associated with activation of two main anti-apoptotic cell signaling pathways (Ras/mitogen-activated protein kinase [MAPK] and PI3K-Akt) and one secondary pathway (phospholipase C-gamma1-protein kinase C [PLC- $\gamma 1-P K C]$ ) simulating meningioma proliferation via autocrine and paracrine mechanisms [13,53]. Interestingly, PDGFRA expression on meningioma cells is rare and might not play an important role in meningioma pathology [52]. Collectively, these findings suggest that ponatinib exerts its effects through inhibition of PDGFRB rather than PDGFRA.

The expression of FLT3 in meningioma has been reported, however, the clinical significance in meningioma remains unclear [22]. Moreover, the mRNA levels of VEGFR1 and $V E G F R 2$ were upregulated upon the treatment in vivo. It is known that the VEGFR1 and VEGFR2 are the targets of ponatinib, and therefore the inhibition of VEGFR by ponatinib may induce a compensatory increased transcription of the corresponding genes, which subsequently led to an upregulated mRNA level of VEGFR1 and VEGFR2 [28,49].

Interestingly, analysis of differentially expressed genes of sequenced xenograft tumors revealed a downregulation of mitochondrial genes and subsequent gene set enrichment analysis indicated mitochondrial dysfunction in ponatinib-treated meningiomas. These 
downregulated genes are vital for the assembling of mitochondrial complex I, III, IV, and V, which are the key components for the respiratory electron transport chain (ETC) [24]. The dysfunction of ETC may generate reactive oxygen species (ROS), which may subsequently induce apoptosis [54]. Several TKis such as ponatinib, sorafenib, and regorafenib have been reported to uncouple components of ETC, induce mitochondrial dysfunction, and thus promote ROS generation $[25,55]$. In line with our findings, ponatinib has been shown to impair the activity of mitochondrial complex I, III, and V in human hepatic HepG2 cells, and eventually impeded the function of the ETC [25]. Furthermore, in chronic eosinophilic leukemia cells, Jin et al. found that ponatinib can induce a release of apoptosis-inducing factor and cytochrome $\mathrm{C}$ from the mitochondria into the cytosol, which in turn triggers the mitochondrial apoptosis pathway [55]. In conclusion, ponatinib seems to negatively affect mitochondria, thus triggering cellular apoptosis.

In humans, the treatment with ponatinib is associated with some adverse events (AE), however their frequencies are low [56]; the most common AEs are cardiovascular adverse events, thrombocytopenia, abdominal pain, anemia, and rash, occurring in a dosedependent fashion [56]. In our study, ponatinib-treated mice did not experience any weight loss during the three weeks of treatment. Moreover, blood parameters of ponatinib-treated mice were not altered except of $\mathrm{MHCH}$, indicating that normal physiological functions are maintained by mice after ponatinib treatment.

\section{Conclusions}

In this work, we demonstrated that ponatinib is highly effective against meningioma in vitro and in vivo while being well-tolerated. Mechanistically, this was achieved presumably through inhibition of the PDGFRA/B-axis and mitochondrial dysfunction. Collectively, this data proposes ponatinib as a promising candidate for targeted therapy for aggressive meningioma.

Supplementary Materials: The following are available online at https: / www.mdpi.com/article / $10.3390 /$ cancers13235898/s1, Figure S1, S2, S3. Figure S1: Ponatinib significantly inhibited the proliferation of meningioma cells, Figure S2: Ponatinib effectively inhibited the tumor growth but did not induce apoptosis in vivo, Figure S3: Gene set enrichment analysis of the receptor tyrosine kinase signaling pathway, Table S1: List of primers, Table S2: List of differentially expressed genes.

Author Contributions: Conceptualization, T.Y. and G.J.; data curation, T.Y. and G.J.; formal analysis, T.Y. and G.J.; funding acquisition, C.H.-M., R.W., G.J. and T.Y.; investigation, T.Y., G.J., J.C., M.A.E., A.M. and C.E.; methodology, G.J., T.Y., J.C., M.A.E., C.E. and A.M.; resources, C.H.-M., A.U., G.J., A.A. and M.M.; software, T.Y., G.J., R.W., C.E., and A.M.; supervision, A.U., C.H.-M. and G.J.; validation, T.Y. and G.J.; visualization, T.Y., G.J. and R.W.; writing—original draft preparation, T.Y.; writingreview and editing, C.H.-M., G.J., T.Y. All authors have read and agreed to the published version of the manuscript.

Funding: This work was supported by China Scholarship Council (T.Y., CSC: 201706010347), Familie Mehdorn Stiftung (G.J.), Physician Scientist Program of the Heidelberg Faculty of Medicine (G.J.), and the German Cancer Aid (R.W., C.H.-M.).

Institutional Review Board Statement: The study was conducted according to the guidelines of the Declaration of Helsinki, and approved by the Institutional Review Board of Regierungspraesidium Karlsruhe, Germany (protocol code: 35-9185.81/G-13/20; date of approval: 18.03.2020).

Informed Consent Statement: Not applicable.

Data Availability Statement: The data presented in this study are available in this article.

Acknowledgments: We thank Farzaneh Kashfi, Ilka Hearn, Ronja Trunk, Lisa Petermann, and Melanie Greibich for their excellent technical assistance.

Conflicts of Interest: The authors declare no potential conflict of interest. 


\section{References}

1. Ostrom, Q.T.; Patil, N.; Cioffi, G.; Waite, K.; Kruchko, C.; Barnholtz-Sloan, J.S. CBTRUS Statistical Report: Primary Brain and Other Central Nervous System Tumors Diagnosed in the United States in 2013-2017. Neuro-Oncology 2020, 22, iv1-iv96. [CrossRef]

2. Holleczek, B.; Zampella, D.; Urbschat, S.; Sahm, F.; von Deimling, A.; Oertel, J.; Ketter, R. Incidence, Mortality and Outcome of Meningiomas: A Population-Based Study from Germany. Cancer Epidemiol. 2019, 62, 101562. [CrossRef] [PubMed]

3. Fuentes, S.; Chinot, O.; Dufour, H.; Paz-Paredes, A.; Métellus, P.; Barrie-Attarian, M.; Grisoli, F. Hydroxyurea treatment for unresectable meningioma. Neurochirurgie 2004, 50, 461-467. [CrossRef]

4. Scorsetti, M.; Alongi, F.; Clerici, E.; Navarria, P.; Simonelli, M.; Rognone, E.; Santoro, A. Temozolomide Combined with Radiotherapy in the Treatment of Recurrent Cranial Meningioma Previously Treated with Multiple Surgical Resections and Two Sessions of Radiosurgery: A Case Report and Literature Review. Tumori 2012, 98, e67-e71. [CrossRef]

5. Clark, V.E.; Erson-Omay, E.Z.; Serin, A.; Yin, J.; Cotney, J.; Özduman, K.; Avşar, T.; Li, J.; Murray, P.B.; Henegariu, O.; et al. Genomic Analysis of Non-NF2 Meningiomas Reveals Mutations in TRAF7, KLF4, AKT1 and SMO. Science 2013, 339, 1077-1080. [CrossRef]

6. Abedalthagafi, M.; Bi, W.L.; Aizer, A.A.; Merrill, P.H.; Brewster, R.; Agarwalla, P.K.; Listewnik, M.L.; Dias-Santagata, D.; Thorner, A.R.; Van Hummelen, P.; et al. Oncogenic PI3K Mutations are as Common as AKT1 and SMO Mutations in Meningioma. Neuro-Oncology 2016, 18, 649-655. [CrossRef] [PubMed]

7. Hadfield, K.D.; Newman, W.G.; Bowers, N.L.; Wallace, A.; Bolger, C.; Colley, A.; McCann, E.; Trump, D.; Prescott, T.; Evans, D.G.R. Molecular Characterisation of SMARCB1 and NF2 in Familial and Sporadic Schwannomatosis. J. Med. Genet. 2008, 45, 332-339. [CrossRef]

8. Shankar, G.M.; Abedalthagafi, M.; Vaubel, R.A.; Merrill, P.H.; Nayyar, N.; Gill, C.M.; Brewster, R.; Bi, W.L.; Agarwalla, P.K.; Thorner, A.R.; et al. Germline and Somatic BAP1 Mutations in High-Grade Rhabdoid Meningiomas. Neuro-Oncology 2017, 19, 535-545. [CrossRef]

9. Goutagny, S.; Nault, J.C.; Mallet, M.; Henin, D.; Rossi, J.Z.; Kalamarides, M. High Incidence of Activating TERT Promoter Mutations in Meningiomas Undergoing Malignant Progression. Brain Pathol. Zurich Switz. 2014, 24, 184-189. [CrossRef]

10. Mawrin, C.; Sasse, T.; Kirches, E.; Kropf, S.; Schneider, T.; Grimm, C.; Pambor, C.; Vorwerk, C.K.; Firsching, R.; Lendeckel, U.; et al. Different Activation of Mitogen-Activated Protein Kinase and Akt Signaling is Associated with Aggressive Phenotype of Human Meningiomas. Clin. Cancer Res. 2005, 11, 4074-4082. [CrossRef]

11. El-Habr, E.A.; Levidou, G.; Trigka, E.-A.; Sakalidou, J.; Piperi, C.; Chatziandreou, I.; Spyropoulou, A.; Soldatos, R.; Tomara, G.; Petraki, K.; et al. Complex Interactions between the Components of the PI3K/AKT/MTOR Pathway, and with Components of MAPK, JAK/STAT and Notch-1 Pathways, Indicate Their Involvement in Meningioma Development. Virchows Arch. 2014, 465, 473-485. [CrossRef]

12. Johnson, M.D.; Reeder, J.E.; O'Connell, M. MKP-3 Regulates PDGF-BB Effects and MAPK Activation in Meningioma Cells. J. Clin. Neurosci. 2015, 22, 752-757. [CrossRef]

13. Johnson, M.; Toms, S. Mitogenic Signal Transduction Pathways in Meningiomas: Novel Targets for Meningioma Chemotherapy? J. Neuropathol. Exp. Neurol. 2005, 64, 1029-1036. [CrossRef] [PubMed]

14. Nakada, S.; Sasagawa, Y.; Tachibana, O.; Iizuka, H.; Kurose, N.; Shioya, A.; Guo, X.; Yamada, S.; Nojima, T. The Clinicopathological Analysis of Receptor Tyrosine Kinases in Meningiomas: The Expression of VEGFR-2 in Meningioma was Associated with a Higher WHO Grade and Shorter Progression-Free Survival. Brain Tumor Pathol. 2019, 36, 7-13. [CrossRef] [PubMed]

15. Figarella-Branger, D.; Vagner-Capodano, A.M.; Bouillot, P.; Graziani, N.; Gambarelli, D.; Devictor, B.; Zattara-Cannoni, H.; Bianco, N.; Grisoli, F.; Pellissier, J.F. Platelet-Derived Growth Factor (PDGF) and Receptor (PDGFR) Expression in Human Meningiomas: Correlations with Clinicopathological Features and Cytogenetic Analysis. Neuropathol. Appl. Neurobiol. 1994, 20, 439-447. [CrossRef] [PubMed]

16. Caltabiano, R.; Barbagallo, G.M.V.; Castaing, M.; Cassenti, A.; Senetta, R.; Cassoni, P.; Albanese, V.; Lanzafame, S. Prognostic Value of EGFR Expression in de Novo and Progressed Atypical and Anaplastic Meningiomas: An Immunohistochemical and Fluorescence in situ Hybridization Pilot Study. J. Neurosurg. Sci. 2013, 57, 139-151.

17. Sharma, P.; Katiyar, V.; Sharma, R.; Gurjar, H.K.; Krishnan, S. Letter: Role of Tyrosine Kinase Inhibitors in Recurrent Meningiomas: Controversies and Promises. Neurosurgery 2018, 82, E181-E183. [CrossRef]

18. Wen, P.Y.; Yung, W.K.A.; Lamborn, K.R.; Norden, A.D.; Cloughesy, T.F.; Abrey, L.E.; Fine, H.A.; Chang, S.M.; Robins, H.I.; Fink, K.; et al. Phase II Study of Imatinib Mesylate for Recurrent Meningiomas (North American Brain Tumor Consortium Study 01-08). Neuro-Oncology 2009, 11, 853-860. [CrossRef]

19. Tuchen, M.; Wilisch-Neumann, A.; Daniel, E.A.; Baldauf, L.; Pachow, D.; Scholz, J.; Angenstein, F.; Stork, O.; Kirches, E.; Mawrin, C. Receptor Tyrosine Kinase Inhibition by Regorafenib/Sorafenib Inhibits Growth and Invasion of Meningioma Cells. Eur. J. Cancer 2017, 73, 9-21. [CrossRef]

20. Norden, A.D.; Raizer, J.J.; Abrey, L.E.; Lamborn, K.R.; Lassman, A.B.; Chang, S.M.; Yung, W.K.A.; Gilbert, M.R.; Fine, H.A.; Mehta, M.; et al. Phase II Trials of Erlotinib or Gefitinib in Patients with Recurrent Meningioma. J. Neurooncol. 2010, 96, $211-217$. [CrossRef]

21. Alexander, P.B.; Wang, X.-F. Resistance to Receptor Tyrosine Kinase Inhibition in Cancer: Molecular Mechanisms and Therapeutic Strategies. Front. Med. 2015, 9, 134-138. [CrossRef] 
22. Andrae, N.; Kirches, E.; Hartig, R.; Haase, D.; Keilhoff, G.; Kalinski, T.; Mawrin, C. Sunitinib Targets PDGF-Receptor and Flt3 and Reduces Survival and Migration of Human Meningioma Cells. Eur. J. Cancer 2012, 48, 1831-1841. [CrossRef] [PubMed]

23. Kaley, T.J.; Wen, P.; Schiff, D.; Ligon, K.; Haidar, S.; Karimi, S.; Lassman, A.B.; Nolan, C.P.; DeAngelis, L.M.; Gavrilovic, I.; et al. Phase II Trial of Sunitinib for Recurrent and Progressive Atypical and Anaplastic Meningioma. Neuro-Oncology 2015, 17, 116-121. [CrossRef] [PubMed]

24. Tabish, T.A.; Narayan, R.J. Mitochondria-Targeted Graphene for Advanced Cancer Therapeutics. Acta Biomater. 2021, 129, 43-56. [CrossRef] [PubMed]

25. Paech, F.; Mingard, C.; Grünig, D.; Abegg, V.F.; Bouitbir, J.; Krähenbühl, S. Mechanisms of Mitochondrial Toxicity of the Kinase Inhibitors Ponatinib, Regorafenib and Sorafenib in Human Hepatic HepG2 Cells. Toxicology 2018, 395, 34-44. [CrossRef]

26. Rodríguez-Hernández, M.A.; de la Cruz-Ojeda, P.; López-Grueso, M.J.; Navarro-Villarán, E.; Requejo-Aguilar, R.; CastejónVega, B.; Negrete, M.; Gallego, P.; Vega-Ochoa, Á.; Victor, V.M.; et al. Integrated Molecular Signaling Involving Mitochondrial Dysfunction and Alteration of Cell Metabolism Induced by Tyrosine Kinase Inhibitors in Cancer. Redox Biol. 2020, 36, 101510. [CrossRef] [PubMed]

27. Rimola, J.; Díaz-González, Á.; Darnell, A.; Varela, M.; Pons, F.; Hernandez-Guerra, M.; Delgado, M.; Castroagudin, J.; Matilla, A.; Sangro, B.; et al. Complete Response under Sorafenib in Patients with Hepatocellular Carcinoma: Relationship with Dermatologic Adverse Events. Hepatology 2018, 67, 612-622. [CrossRef] [PubMed]

28. Tan, F.H.; Putoczki, T.L.; Stylli, S.S.; Luwor, R.B. Ponatinib: A Novel Multi-Tyrosine Kinase Inhibitor against Human Malignancies. OncoTargets Ther. 2019, 12, 635-645. [CrossRef]

29. Ren, M.; Hong, M.; Liu, G.; Wang, H.; Patel, V.; Biddinger, P.; Silva, J.; Cowell, J.; Hao, Z. Novel FGFR Inhibitor Ponatinib Suppresses the Growth of Non-Small Cell Lung Cancer Cells Overexpressing FGFR1. Oncol. Rep. 2013, 29, 2181-2190. [CrossRef]

30. Mologni, L.; Redaelli, S.; Morandi, A.; Plaza-Menacho, I.; Gambacorti-Passerini, C. Ponatinib is a Potent Inhibitor of Wild-Type and Drug-Resistant Gatekeeper Mutant RET Kinase. Mol. Cell. Endocrinol. 2013, 377, 1-6. [CrossRef]

31. Han, Y.; Gu, Z.; Wu, J.; Huang, X.; Zhou, R.; Shi, C.; Tao, W.; Wang, L.; Wang, Y.; Zhou, G.; et al. Repurposing Ponatinib as a Potent Agent against KIT Mutant Melanomas. Theranostics 2019, 9, 1952-1964. [CrossRef] [PubMed]

32. Gozgit, J.M.; Wong, M.J.; Wardwell, S.; Tyner, J.W.; Loriaux, M.M.; Mohemmad, Q.K.; Narasimhan, N.I.; Shakespeare, W.C.; Wang, F.; Druker, B.J.; et al. Potent Activity of Ponatinib (AP24534) in Models of FLT3-Driven Acute Myeloid Leukemia and Other Hematologic Malignancies. Mol. Cancer Ther. 2011, 10, 1028-1035. [CrossRef] [PubMed]

33. De Falco, V.; Buonocore, P.; Muthu, M.; Torregrossa, L.; Basolo, F.; Billaud, M.; Gozgit, J.M.; Carlomagno, F.; Santoro, M. Ponatinib (AP24534) is a Novel Potent Inhibitor of Oncogenic RET Mutants Associated with Thyroid Cancer. J. Clin. Endocrinol. Metab. 2013, 98, E811-E819. [CrossRef]

34. Li, S.Q.; Cheuk, A.T.; Shern, J.F.; Song, Y.K.; Hurd, L.; Liao, H.; Wei, J.S.; Khan, J. Targeting Wild-Type and Mutationally Activated FGFR4 in Rhabdomyosarcoma with the Inhibitor Ponatinib (AP24534). PLoS ONE 2013, 8, e76551. [CrossRef] [PubMed]

35. Garner, A.P.; Gozgit, J.M.; Anjum, R.; Vodala, S.; Schrock, A.; Zhou, T.; Serrano, C.; Eilers, G.; Zhu, M.; Ketzer, J.; et al. Ponatinib Inhibits Polyclonal Drug-Resistant KIT Oncoproteins and Shows Therapeutic Potential in Heavily Pretreated Gastrointestinal Stromal Tumor (GIST) Patients. Clin. Cancer Res. Off. J. Am. Assoc. Cancer Res. 2014, 20, 5745-5755. [CrossRef] [PubMed]

36. Zhang, J.; Zhou, Q.; Gao, G.; Wang, Y.; Fang, Z.; Li, G.; Yu, M.; Kong, L.; Xing, Y.; Gao, X. The Effects of Ponatinib, a Multi-Targeted Tyrosine Kinase Inhibitor, against Human U87 Malignant Glioblastoma Cells. OncoTargets Ther. 2014, 7, 2013-2019. [CrossRef]

37. Gozgit, J.M.; Squillace, R.M.; Wongchenko, M.J.; Miller, D.; Wardwell, S.; Mohemmad, Q.; Narasimhan, N.I.; Wang, F.; Clackson, T.; Rivera, V.M. Combined Targeting of FGFR2 and MTOR by Ponatinib and Ridaforolimus Results in Synergistic Antitumor Activity in FGFR2 Mutant Endometrial Cancer Models. Cancer Chemother. Pharmacol. 2013, 71, 1315-1323. [CrossRef]

38. Faustino-Rocha, A.; Oliveira, P.A.; Pinho-Oliveira, J.; Teixeira-Guedes, C.; Soares-Maia, R.; da Costa, R.G.; Colaço, B.; Pires, M.J.; Colaço, J.; Ferreira, R.; et al. Estimation of Rat Mammary Tumor Volume Using Caliper and Ultrasonography Measurements. Lab Anim. 2013, 42, 217-224. [CrossRef]

39. Subramanian, A.; Tamayo, P.; Mootha, V.K.; Mukherjee, S.; Ebert, B.L.; Gillette, M.A.; Paulovich, A.; Pomeroy, S.L.; Golub, T.R.; Lander, E.S.; et al. Gene Set Enrichment Analysis: A Knowledge-Based Approach for Interpreting Genome-Wide Expression Profiles. Proc. Natl. Acad. Sci. USA 2005, 102, 15545-15550. [CrossRef]

40. Jungwirth, G.; Yu, T.; Moustafa, M.; Rapp, C.; Warta, R.; Jungk, C.; Sahm, F.; Dettling, S.; Zweckberger, K.; Lamszus, K.; et al. Identification of KIF11 as a Novel Target in Meningioma. Cancers 2019, 11, 545. [CrossRef]

41. Jungwirth, G.; Yu, T.; Cao, J.; Eddine, M.A.; Moustafa, M.; Warta, R.; Debus, J.; Unterberg, A.; Abdollahi, A.; Herold-Mende, C. KIF11 Inhibitors Filanesib and Ispinesib Inhibit Meningioma Growth in vitro and in vivo. Cancer Lett. 2021, 506, 1-10. [CrossRef]

42. Abril, J.; de Heredia, M.L.; González, L.; Clèries, R.; Nadal, M.; Condom, E.; Aguiló, F.; Gómez-Zaera, M.; Nunes, V. Altered Expression of 12S/MT-RNR1, MT-CO2/COX2, and MT-ATP6 Mitochondrial Genes in Prostate Cancer. Prostate 2008, 68, $1086-1096$. [CrossRef]

43. Mastrorocco, A.; Ciani, E.; Nicassio, L.; Roelen, B.A.J.; Minervini, F.; Dell'Aquila, M.E. Beauvericin Alters the Expression of Genes Coding for Key Proteins of the Mitochondrial Chain in Ovine Cumulus-Oocyte Complexes. Mycotoxin Res. 2021, 37, 1-9. [CrossRef] [PubMed]

44. Whittle, S.B.; Patel, K.; Zhang, L.; Woodfield, S.E.; Du, M.; Smith, V.; Zage, P.E. The Novel Kinase Inhibitor Ponatinib is an Effective Anti-Angiogenic Agent against Neuroblastoma. Investig. New Drugs 2016, 34, 685-692. [CrossRef] 
45. O'Hare, T.; Shakespeare, W.C.; Zhu, X.; Eide, C.A.; Rivera, V.M.; Wang, F.; Adrian, L.T.; Zhou, T.; Huang, W.-S.; Xu, Q.; et al. AP24534, a Pan-BCR-ABL Inhibitor for Chronic Myeloid Leukemia, Potently Inhibits the T315I Mutant and Overcomes Mutation-Based Resistance. Cancer Cell 2009, 16, 401-412. [CrossRef] [PubMed]

46. Petrilli, A.M.; Garcia, J.; Bott, M.; Plati, S.K.; Dinh, C.T.; Bracho, O.R.; Yan, D.; Zou, B.; Mittal, R.; Telischi, F.F.; et al. Ponatinib Promotes a G1 Cell-Cycle Arrest of Merlin/NF2-Deficient Human Schwann Cells. Oncotarget 2017, 8, 31666-31681. [CrossRef] [PubMed]

47. Liu, C.; Mu, X.; Wang, X.; Zhang, C.; Zhang, L.; Yu, B.; Sun, G. Ponatinib Inhibits Proliferation and Induces Apoptosis of Liver Cancer Cells, but Its Efficacy is Compromised by Its Activation on PDK1/Akt/MTOR Signaling. Molecules 2019, $24,1363$. [CrossRef]

48. Nair, A.B.; Jacob, S. A Simple Practice Guide for dose Conversion between Animals and Human. J. Basic Clin. Pharm. 2016, 7, 27-31. [CrossRef]

49. Gozgit, J.M.; Wong, M.J.; Moran, L.; Wardwell, S.; Mohemmad, Q.K.; Narasimhan, N.I.; Shakespeare, W.C.; Wang, F.; Clackson, T.; Rivera, V.M. Ponatinib (AP24534), a Multitargeted Pan-FGFR Inhibitor with Activity in Multiple FGFR-Amplified or Mutated Cancer Models. Mol. Cancer Ther. 2012, 11, 690-699. [CrossRef]

50. Mawrin, C. Animal Models of Meningiomas. Chin. Clin. Oncol. 2017, 6, S6. [CrossRef]

51. Hirata, E.; Sahai, E. Tumor Microenvironment and Differential Responses to Therapy. Cold Spring Harb. Perspect. Med. 2017, 7, a026781. [CrossRef]

52. Wang, J.-L.; Nistér, M.; Hermansson, M.; Westermark, B.; Pontén, J. Expression of PDGF $\beta$-Receptors in Human Meningioma Cells. Int. J. Cancer 1990, 46, 772-778. [CrossRef]

53. Sherman, W.J.; Raizer, J.J. Chemotherapy: What is Its Role in Meningioma? Expert Rev. Neurother. 2012, 12, 1189-1196. [CrossRef]

54. Weinberg, F.; Chandel, N.S. Reactive Oxygen Species-Dependent Signaling Regulates Cancer. Cell. Mol. Life Sci. 2009 , 66, 3663. [CrossRef]

55. Jin, Y.; Ding, K.; Li, H.; Xue, M.; Shi, X.; Wang, C.; Pan, J. Ponatinib Efficiently Kills Imatinib-Resistant Chronic Eosinophilic Leukemia Cells Harboring Gatekeeper Mutant T674I FIP1L1-PDGFR $\alpha$ : Roles of Mcl-1 and $\beta$-Catenin. Mol. Cancer $2014,13,17$. [CrossRef]

56. Chan, O.; Talati, C.; Isenalumhe, L.; Shams, S.; Nodzon, L.; Fradley, M.; Sweet, K.; Pinilla-Ibarz, J. Side-Effects Profile and Outcomes of Ponatinib in the Treatment of Chronic Myeloid Leukemia. Blood Adv. 2020, 4, 530-538. [CrossRef] 